\title{
A Comparative Study of Endoscopic versus Microscopic Cartilage Type I Tympanoplasty
}

\author{
Dipesh Shakya1@ Arun KC ${ }^{2} \quad$ Ajit Nepal $^{3}$ \\ 1 Department of Otorhinolaryngology, Civil Service Hospital, \\ Kathmandu, Nepal \\ 2 Department of Otorhinolaryngology, National Academy of Medical \\ Sciences, Kathmandu, Nepal \\ ${ }^{3}$ Department of Otorhinolaryngology, Patan Academy of Health \\ Science, Lalitpur, Nepal
}

\begin{abstract}
Address for correspondence Dr. Dipesh Shakya, Department of otorhinolaryngology, MD, MS, Civil Service Hospital, Minbhawan Kathmandu, Kathmandu, 44600, Nepal (e-mail: dipeshent@yahoo.com).
\end{abstract}

Int Arch Otorhinolaryngol 2020;24:e80-e85.

\begin{abstract}
Introduction The use of endoscope is rapidly increasing in otological and neurootological surgery in the last 2 decades. Middle ear surgeries, including tympanoplasty, have increasingly utilized endoscopes as an adjunct to or as a replacement for the operative microscope. Superior visualization and transcanal access to diseases normally managed with a transmastoid approach are touted as advantages with the endoscope.

Objectives The present study aimed to compare the outcomes of endoscopic and microscopic cartilage tympanoplasty (Type I)

Methods This was a retrospective comparative study of 70 patients ( 25 males and 45 females) who underwent type I tympanoplasty between March 2015 and April 2016. The subjects were classified into 2 groups: endoscopic tympanoplasty $(E T, n=35)$, and microscopic tympanoplasty (MT, $n=35$ ). Tragal cartilage was used as a graft and technique used was cartilage shield tympanoplasty in both groups. Demographic data, perforation size of the tympanic membrane at the preoperative state, operation time, hearing outcome, and graft success rate were evaluated.

Results The epidemiological profiles, the preoperative hearing status, and the perforation size were similar in both groups. The mean operation time of the MT group ( $52.63 \pm 8.68$ minutes) was longer than that of the ET group $(48.20 \pm 10.37$ minutes), but the difference was not statistically significant. The graft success rates 12 weeks postoperatively were $91.42 \%$ both in the ET and MT groups, that is, 32/35; and these values were not statistically significantly different. There was a statistically

Keywords

- tympanoplasty

- cartilage

- microscope

- endoscope significant improvement in hearing within the groups, both pre- and postoperatively, but there was no difference between the groups.

Conclusion Endoscopic tympanoplasty is a minimally invasive surgery with similar graft success rate, comparable hearing outcomes and shorter operative time period as compared to microscopic use.
\end{abstract}

received

April 17, 2019

accepted

May 21, 2019
DOI https://doi.org/

10.1055/s-0039-1693139.

ISSN 1809-9777.
Copyright (e) 2020 by Thieme Revinter

Publicações Ltda, Rio de Janeiro, Brazil
License terms

ㄷ) (i) $\ominus$ (\$) 


\section{Introduction}

Chronic otitis media (COM) is one of the most common problems in otology, which leads to permanent changes in the tympanic membrane and/or in the structures of the middle ear. ${ }^{1}$ It is further classified as non-cholesteatomatous and cholesteatomatous. ${ }^{2}$

Type I tympanoplasty is the repair of the perforation of the tympanic membrane, and it was first performed by Berthold (1878), later popularized by Wullstein and Zollner (1950). ${ }^{3}$

Although the temporalis fascia is still being used as graft material, it has been largely replaced by cartilage due to its stability and long-term uptake result. ${ }^{4}$

A microscope was first used by Swedish otologist Carl Olof Nylen in 1921, but it was monocular. Later Binocular microscope was used by Gunner Holmgren in 1922; however, this type of microscope was not popular due to poor light quality, limited field of vision, instability and very short focal distance until new model appeared in 1951 which was perfected by Littmann and the Zeiss company that replaced all other models. ${ }^{5}$ The microscope gives the advantage of magnified vision, good depth perception, and utilizes two hand techniques. However, it has the disadvantages of giving straight line vision and of not providing a good vision of deep recesses. ${ }^{6}$

The use of the endoscope is rapidly increasing in otological and neuro-otological surgery in the last 2 decades. Middle ear surgeries, including tympanoplasty, have increasingly utilized endoscopes as an adjunct to or as a replacement for the operative microscope. Superior visualization and transcanal access to diseases normally managed with the transmastoid approach are touted as advantages of the endoscope. ${ }^{7}$ The objectives of the present study were to compare the outcome of endoscopic and microscopic cartilage Type I tympanoplasty regarding graft uptake rate, hearing outcome, and operation time.

\section{Methods}

We performed a retrospective comparative study of prospectively maintained data of 70 patients ( 25 males and 45 females) who underwent type I tympanoplasty from March 2015 to April 2016. The subjects were classified into 2 groups: endoscopic tympanoplasty group (ET, $n=35$ ), and microscopic tympanoplasty group (MT, $n=35$ ). All of the surgeries used tragal cartilage as graft and shield technique used. Demographic data, perforation size of the tympanic membrane at the preoperative state, operation time, and graft success rate were evaluated.

For the ET group, all of the cases were performed transcanally, whereas in the MT group the permeatal and postaural approaches were used. Three cases of the MT group needed the postaural approach due to the lack of vision of the anterior margin.

All of the procedures were performed by two surgeons (the first two authors of the present article). Patients aged $<13$ years old were operated under general anesthesia, and those $\geq 13$ years old were operated under local anesthesia. Cases operated under local anesthesia were performed on a day-case

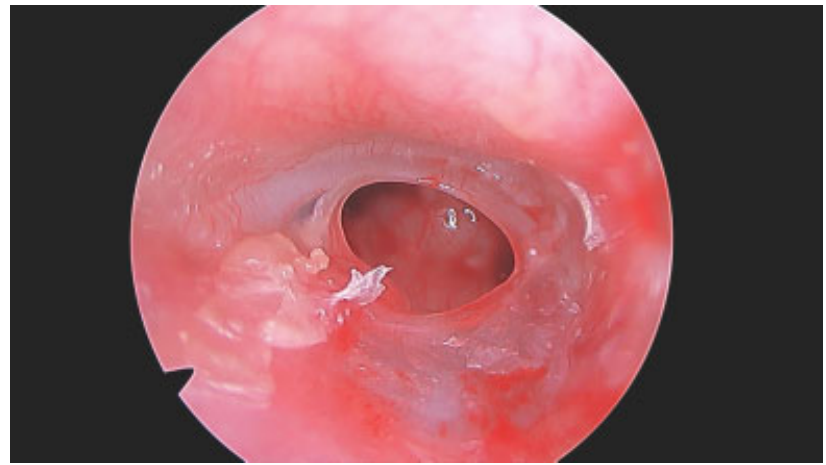

Fig. 1 Preoperative perforation

basis without admission. Ethical clearance was obtained from the Institutional Review Board. A local antibiotic and steroid treatment was performed in case of preoperative inflammation of the tympanic cavity. A tragal cartilage graft was harvested, and the perichondrium was removed on both sides. The margin of the perforation was refreshed, and the drum remnant was removed from the handle of the malleus. The mobility of the ossicular chain was checked. The graft was shaped to the size of the perforation. Gelfoams were kept in the middle ear accordingly. For the posterior perforation, the graft was placed in the underlay technique, medial to the handle of the malleus, to the tympanic membrane, and to the annulus. For central, anterior and subtotal perforations, the graft was notched to fit the handle of the malleus and placed in the over-underlay technique. All of the cases were then reinforced using the perichondrium. The tympanomeatal flap was pulled down and the annulus was meticulously inserted in the sulcus. The external auditory canal (EAC) was packed with gelfoam and then with ear pack, which was removed after 7 days. ( - Figs. 1 to 6 )

The patients were followed up at 6 weeks, 12 weeks, and 6 months. The average on 4 frequencies $(0.5 ; 1.0 ; 2.0$; and $3.0 \mathrm{kHz}$ ) of hearing thresholds in air and bone conduction and the air-bone gap ( $\mathrm{ABG}$ ) were evaluated 7 days before the surgery and 12 weeks afterwards.

Data were analyzed as graft uptake rate and as change between pre- and postoperative hearing. Data were analyzed using the Fisher exact test, the chi-squared test, and the dependent and independent t-test in IBM SPSS Statistics for Windows, Version 23.0 (IBM Corp., Armonk, NY, USA). The level of statistical significance was set at $p<0.05$.

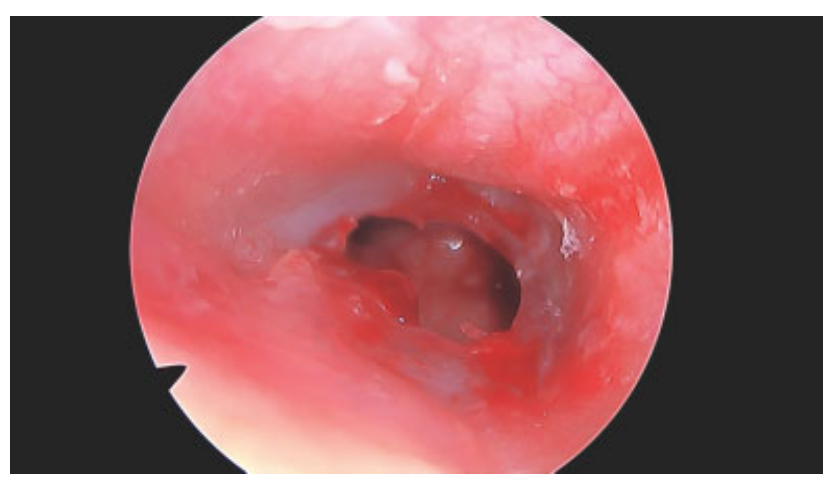

Fig. 2 Margin freshened 


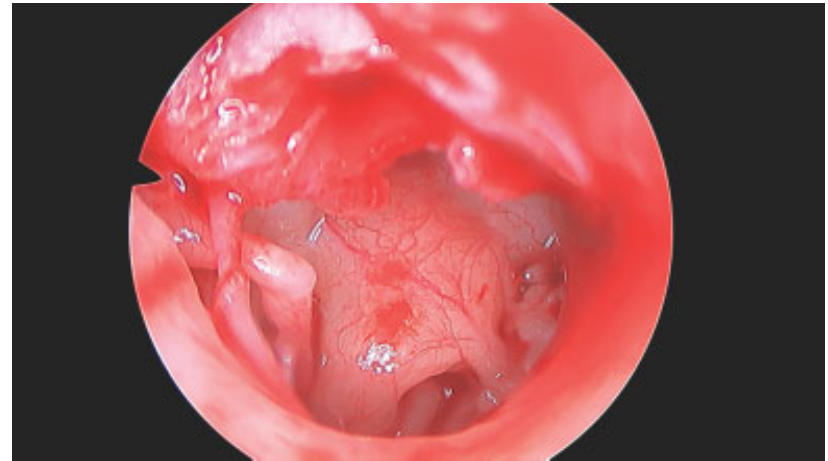

Fig. 3 Middle ear and ossicles exposed

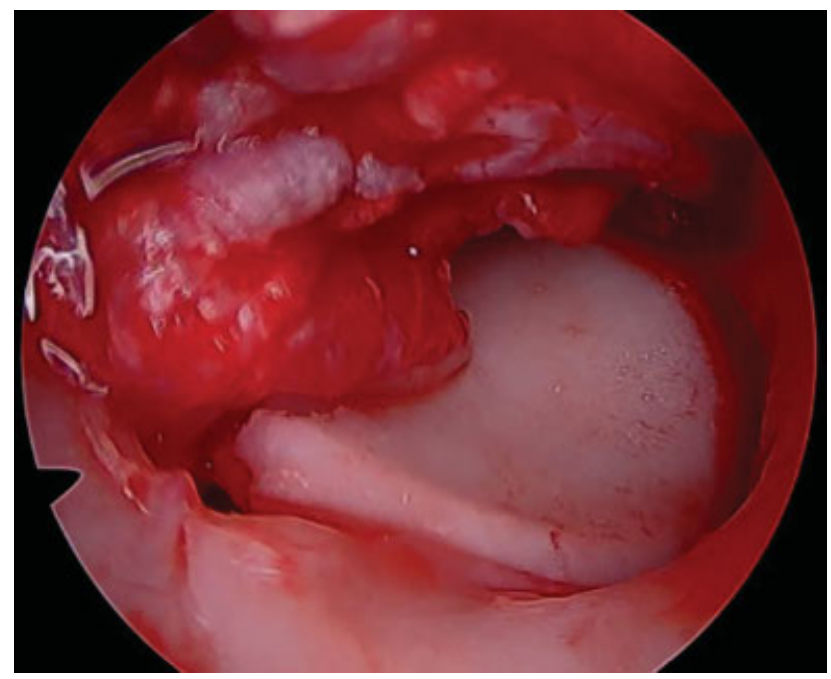

Fig. 4 Cartilage graft placed

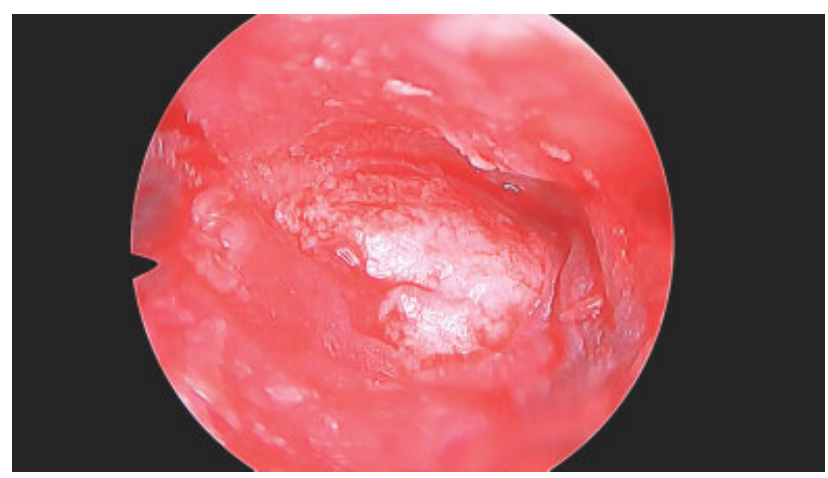

Fig. 5 Perichondrium reinforced

\section{Results}

The epidemiological profiles, the preoperative hearing status, and the perforation size were similar in both groups, as shown in - Table 1. In the ET group, the mean age of the patients was $31.34 \pm 14.89$ years old, ranging from 12 to 65 years old, and in the MT group, the mean age of the patients was $25.86 \pm 9.43$ years old, ranging from 12 to 50 years old. There was no statistically significant difference between the two age groups $(p=0.070)$.

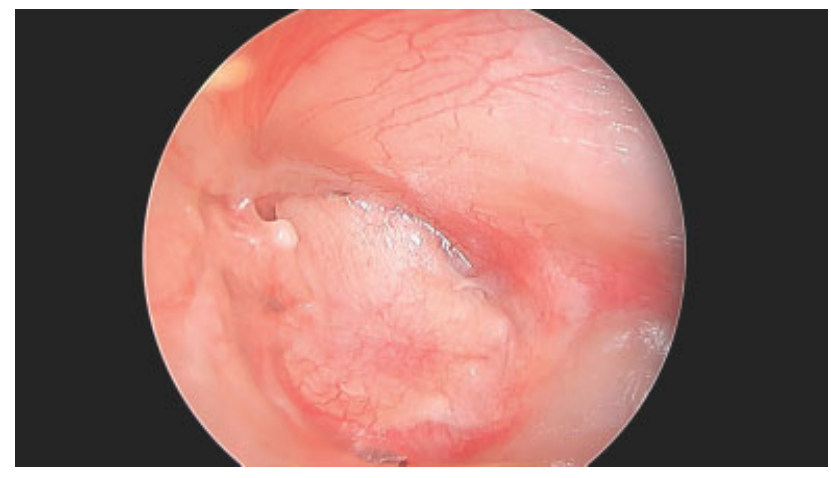

Fig. 6 Graft uptake after 12 weeks

Table 1 Pre- and postoperative hearing outcomes

\begin{tabular}{|c|c|c|c|}
\hline & $\begin{array}{l}\text { Endoscopic } \\
\text { tympanoplasty } \\
\text { group }\end{array}$ & $\begin{array}{l}\text { Microscopic } \\
\text { tympanoplasty } \\
\text { group }\end{array}$ & \\
\hline Enrolled & 35 & 35 & \\
\hline \multicolumn{4}{|l|}{$\begin{array}{l}\text { Age } \\
\text { (years old) }\end{array}$} \\
\hline Range & $12-65$ & $12-50$ & \\
\hline Mean & $31.34 \pm 14.89$ & $25.86 \pm 9.43$ & $p$-value 0.070 \\
\hline \multicolumn{4}{|l|}{ Gender } \\
\hline Male & 14 & 11 & \\
\hline Female & 21 & 24 & \\
\hline Ratio & 0.66 & 0.45 & $p$-value 0.618 \\
\hline \multicolumn{4}{|l|}{ Site } \\
\hline Left & 20 & 19 & \\
\hline Right & 15 & 16 & \\
\hline Ratio & 1.33 & 1.18 & $p$-value 1.00 \\
\hline $\begin{array}{l}\text { Perforation } \\
\text { size (\%) }\end{array}$ & $66.86 \pm 20.15$ & $67.57 \pm 17.87$ & $p$-value 0.876 \\
\hline \multicolumn{4}{|l|}{ Graft } \\
\hline Uptake & 32 (91.42\%) & 32 (91.42\%) & \\
\hline Failure & $3(8.57 \%)$ & $3(8.57 \%)$ & $p$-value 1.00 \\
\hline $\begin{array}{l}\text { Operation } \\
\text { time } \\
\text { (minutes) }\end{array}$ & $48.20 \pm 10.37$ & $52.63 \pm 8.68$ & $p$-value 0.57 \\
\hline \multicolumn{4}{|l|}{$\begin{array}{l}\text { Follow-up } \\
\text { (weeks) }\end{array}$} \\
\hline Range & $5-29$ & $5-49$ & \\
\hline Mean & $12.15 \pm 6.31$ & $17.11 \pm 11.43$ & $p$-value 0.028 \\
\hline
\end{tabular}

There were 14 males and 21 females in the ET group, and 11 males and 24 females in the MT group, which was not statistically different $(p=0.618)$.

Based on the laterality of the disease, in the ET group, 20 cases were on left side, and 15 were on the right side. In the MT group, 19 cases were on the left side, and 16 on the right side. Both were statistically insignificant $(p=1.00)$. The mean perforation size on percentage was $66.86 \pm 20.15$ on the ET group, and $67.57 \pm 17.87$ on the MT group. Both group based on perforation size was not statistically significant $(p=0.876)$. 
The graft success rates at 12 weeks postoperatively were 91.42\% both in the ET and MT groups, that is, 32/35; and these values were not statistically significantly different $(p=1.00)$.

Hearing outcomes were as shown in - Tables 2 to $\mathbf{5}$. There was a highly statistically significant hearing outcome before and after the surgery in both the ET and the MT groups. However, there was no change in hearing outcomes between the two groups. Thus, the hearing outcome did not change with use either of the endoscope or of the microscope.

The mean operation time of the MT group $(52.63 \pm 8.68$ minutes) was longer than that of the ET group ( $48.20 \pm 10.37$ minutes), but not statistically different $(p=0.57)$.

\section{Discussion}

The microscope has been used as the ideal operative tool for tympanoplasty. The endoscope has been now rapidly used for tympanoplasty since the first article published by elGuindy in $1992 .{ }^{8}$ Even tympanomastoidectomy, which was traditionally performed using a microscope, is currently being performed using an endoscope. ${ }^{9}$

Our study showed no differences between the graft closure rates between the 2 groups $(p=1.00)$. Similarly, there was no statistically significant difference obtained in the demographic profile, in the hearing outcomes, and in the operation time between the 2 groups $(p>0.05)$. The results obtained were comparable to those of other studies.

The graft uptake rate both in the ET and in the MT groups was $32 / 35(91.42 \%)$ at the 6 -month follow-up. The operation time for the ET group was $48.20 \pm 10.37$ minutes, and for the MT group, it was $52.63 \pm 8.68$ minutes; although it was shorter for the ET group, the difference was not statistically significant $(p=0.57)$. However, three cases in the MT group needed the postaural approach due to the lack of vision of the anterior margin of the perforation. The hearing outcome was

Table 2 Endoscopic tympanoplasty group

\begin{tabular}{|l|l|l|l|l|l|l|}
\hline \multicolumn{2}{|c|}{} & Mean & $n$ & Standard deviation & Standard error of mean & p-value \\
\hline \multirow{3}{*}{ Pair 1 } & Preoperative ACT & 43.7143 & 35 & 11.32526 & 1.91432 & 0.000 \\
\cline { 2 - 7 } & Postoperative ACT & 32.6786 & 35 & 14.60932 & 2.46943 & \\
\hline \multirow{2}{*}{ Pair 2 } & Preoperative ABG & 29.4143 & 35 & 9.85426 & 1.66567 & 0.000 \\
\cline { 2 - 8 } & Postoperative ABG & 20.6000 & 35 & 11.33419 & 1.91583 & \\
\hline
\end{tabular}

Abbreviations: ABG, air-bone Gap; ACT, air conduction threshold.

Table 3 Microscopic tympanoplasty group

\begin{tabular}{|l|l|l|l|l|l|l|}
\hline \multicolumn{2}{|c|}{} & Mean & $n$ & Standard deviation & Standard error of mean & p-value \\
\hline \multirow{3}{*}{ Pair 1 } & Preoperative ACT & 44.9643 & 35 & 12.21922 & 2.06543 & 0.000 \\
\cline { 2 - 7 } & Postoperative ACT & 33.2857 & 35 & 14.08706 & 2.38115 & \\
\hline \multirow{2}{*}{ Pair 2 } & Preoperative ABG & 29.0500 & 35 & 11.60103 & 1.96093 & 0.000 \\
\cline { 2 - 7 } & Postoperative ABG & 19.6071 & 35 & 10.54913 & 1.78313 & \\
\hline
\end{tabular}

Abbreviations: ABG, air-bone Gap; ACT, air conduction threshold.

Table 4 Pre- and postoperative air conduction threshold (endoscopic versus microscopic groups)

\begin{tabular}{|l|l|l|l|l|l|l|}
\hline & Groups & $\boldsymbol{n}$ & Mean & Standard deviation & Standard error of mean & $\boldsymbol{p}$-value \\
\hline \multirow{3}{*}{ Preoperative ACT } & ET & 35 & 43.7143 & 11.32526 & 1.91432 & .405 \\
\cline { 2 - 8 } & MT & 35 & 44.9643 & 12.21922 & 2.06543 & .825 \\
\hline \multirow{2}{*}{ Postoperative ACT } & ET & 35 & 32.6786 & 14.60932 & 2.46943 & 2.38115 \\
\cline { 2 - 8 } & MT & 35 & 33.2857 & 14.08706 & & \\
\hline
\end{tabular}

Abbreviations: ACT, air conduction threshold; ET, endoscopic tympanoplasty group; MT, microscopic tympanoplasty group.

Table 5 Pre- and postoperative air-bone gap (endoscopic versus microscopic groups)

\begin{tabular}{|l|l|l|l|l|l|l|}
\hline & Groups & $\boldsymbol{n}$ & Mean & Standard deviation & Standard error of mean & p-value \\
\hline \multirow{3}{*}{ Preoperative ABG } & ET & 35 & 29.4143 & 9.85426 & 1.66567 & .456 \\
\cline { 2 - 8 } & MT & 35 & 29.0500 & 11.60103 & 1.96093 & .572 \\
\hline \multirow{2}{*}{ Postoperative ABG } & ET & 35 & 20.6000 & 11.33419 & 1.91583 & 1.78313 \\
\cline { 2 - 8 } & MT & 35 & 19.6071 & 10.54913 & & \\
\hline
\end{tabular}

Abbreviations: ABG, air-bone gap; ET, endoscopic tympanoplasty group; MT, microscopic tympanoplasty group. 
not statistically significant between the groups but had significant results within the groups.

Huang et al performed a similar study in 2016 between 2 groups, microscopic and endoscopic, using the tragal cartilage shield technique, and he had $96 \%$ graft uptake results in both groups at 6 months of follow-up. The operation time in the endoscopic group was of $50.4 \pm 13.4$ minutes, and of $75.5 \pm 20$ minutes in the microscopic group, with $p=0.0001$. Endoscope use revealed to have a shorter operative time than the microscopic group, with a statistically significant result. ${ }^{10}$

A study performed by Choi et al in 2016 that compared endoscopic and microscopic tympanoplasty had $100 \%$ graft uptake in the endoscopic group $(n=25)$ and 95.8\% $(n=48)$ in the microscopic group, which was not statistically significant $(p=0.304)$, with a mean follow-up of 6.4 months (range: $3-$ 11 months). The mean operation time in the microscopic group was of $88.9 \pm 28.5$ minutes, and of $68.2 \pm 22.1$ minutes in the endoscopic group $(p=0.002)$. It revealed that endoscope use had reduced the operative time significantly, which resulted in less exposure to general anesthesia. ${ }^{11}$

A similar study was performed in 2015 by Mokbel et al, who compared endoscopic and microscopic tympanoplasty, with 40 cases in each group, with an uptake rate of $100 \%$ in the endoscopic group and of $90 \%$ in the microscopic group, with a follow-up range between 6 and 24 months. The operation time was of $40 \pm 5.50$ minutes in the endoscopic group, and of $55 \pm 10.50$ minutes in the microscopic group $(p<0.0001) .^{12}$ Another study, performed in 2017 by Jyothi et al, compared microscopic with endoscopic myringoplasty, with 60 cases in each group. They had and uptake rate of $91.67 \%$ in the endoscopic group and of $93.3 \%$ in the microscopic group at 1 year of follow-up. They had a mean operative time of 60 minutes in the endoscopic group and of 120 minutes in the endoscopic group. ${ }^{13}$

A prospective randomized controlled trial performed in 2017 by Kaya et al had 13 patients presenting with bilateral chronic otitis media, and performed microscopic and endoscopic ear surgery in the same patients. They had a graft uptake of $100 \%$ in both groups at 12 months of follow-up. The operative time was of $36 \pm 4.20$ minutes in the endoscopic group and of $69.38 \pm 216.11$ minutes in the microscopic group, a difference that was statistically significant. ${ }^{14}$

In 2015, Awad et al performed endoscopic cartilage type I tympanoplasty in 36 pediatric cases, whose age ranged from 13 to 17 years old, with an uptake rate of $90 \%$ at 6 months of follow-up, with a mean operative time of $55.03 \pm 2.50$ minutes. $^{15}$

In 2015, Özgür et al submitted 53 patients to endoscopic cartilage tympanoplasty, with a graft uptake of $92.5 \%$ at 6 postoperative months, and a mean operative time of $49.4 \pm 8.1$ minutes. $^{16}$

All of the aforementioned studies had significant hearing improvement pre- and postoperatively within the groups and no change between the groups. Similarly, all of the aforementioned studies performed microscopic tympanoplasty with either the postaural or the endaural approach. However, for the homogeneity of the present study, we included microscopic and endoscopic both groups, with only the transcanal approach. There were 3 cases in the MT group that were operated with the postaural approach and it was excluded in average operative time period.

The microscope is considered as the gold standard for the otological procedures, as it provides stereoscopic vision, better depth perception, and bimanual handling. ${ }^{10}$ The first reported case of endoscopic tympanoplasty was by el-Guindy in $1992 .{ }^{8}$

Several studies have already proven that the endoscope significantly reduces the operative time due to the lack of necessity to see the recesses, to its wide vision, and to the lack of necessity to perform postoperative suturing.

This has helped patients to have a fast recovery, a shorter hospital stay, and a lower financial burden, which is especially helpful for developing countries like ours. Newer highdefinition cameras have provided better image quality to access blind sacs, middle ear spaces that would be impossible to be visible by microscope. ${ }^{17}$

There are also limitations to endoscopic ear surgery. It is a one-handed surgery and there is lack of depth perception. ${ }^{18}$ Both of these limitations can be overcome by experience and practice.

Sometimes, its difficult to negotiate instruments in narrow canal along with endoscope, and bleeding makes the surgery hard to deal with. There are studies that give us tips about how to handle bleeding during endoscopic surgery. ${ }^{19}$

We did not find any difficulty while performing endoscopic tympanoplasty. It offered comparable results between the MT and ET groups with respect to graft uptake and hearing outcomes. The ET group had a slightly shorter operative time than the MT group.

\section{Conclusion}

With use of endoscope, minimal invasive tympanoplasty can be possible with similar graft success rate and shorter operative time period as compared to microscope.

Conflicts of Interests

The authors have no conflicts of interests to disclose.

\section{References}

1 Cabra J, Moñux A. Efficacy of cartilage palisade tympanoplasty: randomized controlled trial. Otol Neurotol 2010;31(04):589-595

2 Fukuchi I, Cerchiari DP, Garcia E, Rezende CE, Rapoport PB. Tympanoplasty: surgical results and a comparison of the factors that may interfere in their success. Rev Bras Otorrinolaringol (Engl Ed) 2006;72(02):267-271

3 Dornhoffer JL. Surgical management of the atelectatic ear. Am J Otol 2000;21(03):315-321

4 Beutner D, Huttenbrink KB, Stumpf R, et al. Cartilage plate tympanoplasty. Otol Neurotol 2010;31(01):105-110

5 Mudry A. History of myringoplasty and tympanoplasty type I. Otolaryngology-head and neck surgery: official journal of American Academy of Otolaryngology-. Head Neck Surg 2008;139(05):613-614

6 Tarabichi M. Endoscopic transcanal middle ear surgery. Indian J Otolaryngol Head Neck Surg 2010;62(01):6-24

7 Yadav SP, Aggarwal N, Julaha M, Goel A. Endoscope-assisted myringoplasty. Singapore Med J 2009;50(05):510-512

8 el-Guindy A. Endoscopic transcanal myringoplasty. JLaryngol Otol 1992;106(06):493-495 
9 Bedajit RK, Mallik P, Kumar P, et al. Endoscopic transcanal mastoidectomy with tympanoplasty. Natl J Otorhinolaryngol Head Neck Surg 2015;3(12):10-11

10 Huang TY, Ho KY, Wang LF, Chien CY, Wang HM. A Comparative Study of Endoscopic and Microscopic Approach Type 1 Tympanoplasty for Simple Chronic Otitis Media. J Int Adv Otol 2016;12 (01):28-31

11 Choi N, Noh Y, Park W, et al. Comparison of endoscopic tympanoplasty to microscopic tympanoplasty. Clin Exp Otorhinolaryngol 2017;10(01):44-49

12 Mokbel KM, Moneir W, Elsisi H, et al. Endoscopic Transcanal Cartilage Myringoplasty for Repair of Subtotal Tympanic Membrane Perforation: A Method to Avoid Postauricular Incision. J Otolaryngol Rhinol 2015;1:010

13 Jyothi AC, Shrikrishna BH, Kulkarni NH, Kumar A. Endoscopic Myringoplasty Versus Microscopic Myringoplasty in Tubotympanic CSOM: A Comparative Study of 120 Cases. Indian J Otolaryngol Head Neck Surg 2017;69(03):357-362
14 Kaya I, Sezgin B, Sergin D, et al. Endoscopic versus microscopic type 1 tympanoplasty in the same patients: a prospective randomized controlled trial. Eur Arch Otorhinolaryngol 2017;274 (09):3343-3349

15 Awad OG, Hamid KA. Endoscopic type 1 tympanoplasty in pediatric patients using tragal cartilage. JAMA Otolaryngol Head Neck Surg 2015;141(06):532-538

16 Özgür A, Dursun E, Erdivanli OC, et al. Endoscopic cartilage tympanoplasty in chronic otitis media. J Laryngol Otol 2015; 129(11):1073-1077

17 Kanona H, Virk JS, Owa A. Endoscopic ear surgery: A case series and first United Kingdom experience. World J Clin Cases 2015;3 (03):310-317

18 Kuo CH, Wu HM. Comparison of endoscopic and microscopic tympanoplasty. Eur Arch Otorhinolaryngol 2017;274(07):2727-2732

19 Anschuetz L, Bonali M, Guarino P, et al. Management of bleeding in exclusive endoscopic ear surgery: pilot clinical experience. Otolaryngol Head Neck Surg 2017;157(04):700-706 